\title{
Biotransformation of myrcene by Pseudomonas aeruginosa
}

\author{
Akbar Esmaeili and Elham Hashemi
}

\begin{abstract}
Background: Dihydrolinalool and terpineol are sources of fragrances that provide a unique volatile terpenoid alcohol of low toxicity and thus are widely used in the perfumery industry, in folk medicine, and in aromatherapy. They are important chemical constituents of the essential oil of many plants. Previous studies have concerned the biotransformation of limonene by Pseudomonas putida. The objective of this research was to study biotransformation of myrcene by Pseudomonas aeruginosa. The culture preparation was done using such variables as different microbial methods and incubation periods to obtain maximum cells of $P$. aeruginosa for myrcene biotransformation.

Results: It was found that myrcene was converted to dihydrolinalool and 2,6-dimethyloctane in high percentages. The biotransformation products were identified by Fourier-transform infrared spectroscopy (FT-IR), ultraviolet (UV) analysis, gas chromatography (GC), and gas chromatography-mass spectroscopy (GC-MS). Comparison of the different incubation times showed that 3 days was more effective, the major products being 2,6-dimethyloctane (90.0\%) and $\alpha$-terpineol (7.7\%) and comprising 97.7\%. In contrast, the main compounds derived for an incubation time of 1.5 days were dihydrolinalool (79.5\%) and 2,6-dimethyloctane (9.3\%), with a total yield of $88.8 \%$.
\end{abstract}

\section{Background}

Dihydrolinalool and 2,6-dimethyloctane of low toxicity are widely used in the perfumery industry. They are important chemical constituents of the essential oil of many plants, with widespread applications in folk medicine and in aromatherapy [1].

In the course of work related to bioconversion of monoterpene by fungi, the biotransformation of myrcene by Pseudomonas aeruginosa (PTCC 1074) was investigated. The biotransformation of limonene by P. putida has been reported [2,3]. The bioconversion of neryl acetate by Aspergillus niger has also been described $[4,5]$. Some investigations have showed that the main reaction to liquefied $A$. niger was hydrolysis of terpene to 8-hydroxy derivatives [6].

Microorganisms and their enzymes have proven to be versatile biocatalysts [7] and are extensively used for biotransformation of various terpenoids $[8,9]$.

The majority of biotransformations of terpenoids have been performed on monoterpenoids, which are the main

\footnotetext{
* Correspondence: akbaresmaeili@yahoo.com

Department of Chemical Engineering, North Tehran Branch, Islamic Azad University, P.O. Box 19585/936, Tehran, Iran
}

constituents of many essential oils. The characteristic organoleptic properties of limonene and its usage in food and other applications have led to extensive work on its synthesis and microbial conversions [10-13]. However, most studies dealing with microbial conversion of limonene have reported low yields of products due to volatility of the substrate and the toxicity of limonene to most of the microorganisms $[14,15]$. The present study was aimed at the screening of microorganisms, and in the course of the survey a strain of $P$. aeruginosa was shown to successfully metabolize dihydrolinalool and 2,6-dimethyldoctane. Among the two bioconversion products, the alcohol compound is of particular importance, since it has been reported by several researchers that the alcohol compound derived from lavender (Lavandula angustifolia) has chemopreventive properties against liver, mammary, and lung carcinogenesis $[16,17]$.

In 1964 the use of the sporulated surface cultures method suggested that geraniol was converted to dihydrolinalool and partially oxidized to citral [18]. Microbial transformation of geraniol and nerol by the sporulated surface cultures method using five $A$. niger strains and three Penicillium strains has been compared with the 
submerged liquid method [19]. Several researchers have used different fungi to bioconvert citral [20-24].

\section{Experimental}

Malt extract, peptone, and yeast extract were purchased from Merck \& Co., USA. The substrate and the product myrcene were purchased from Sigma Chemicals Co., USA. Other chemicals of analytical grade were obtained from standard sources. A $0.1 \mathrm{M}$ acetate buffer ( $\mathrm{pH}$ 5.5) was prepared.

\section{Microorganisms and cultural conditions}

A strain of Pseudomonas aeruginosa identified according to the Persian Type Culture Collection (PTCC 1074) was purchased from Iranian Research Organization for Science \& Technology, Tehran, Iran.

\section{Fermentation procedure}

Fermentation was carried out in 250-ml Erlenmeyer flasks containing $100 \mathrm{ml}$ of medium and the microorganism P. aeruginosa PTCC 1074. The flasks were divided into three sets with four containing 1.0\% (V/V) of myrcene to determine the optimum concentration. The flasks were incubated for 1.5 and 3 days at $30^{\circ} \mathrm{C}$. Simultaneously, a control experiment was carried out without microorganisms by adding substrate directly into the sterile broth.

\section{Culture medium}

The culture medium contained $0.3 \%$ malt extract, $0.3 \%$ yeast extract, $0.5 \%$ peptone, and $1.0 \%$ glucose in distilled water ( $\mathrm{pH} 7.0$ for yeast).

\section{Agarose entrapment}

An agarose solution was prepared by dissolving agarose $(15 \% \mathrm{~W} / \mathrm{V})$ in water at $100^{\circ} \mathrm{C}$, which was then cooled to $40^{\circ} \mathrm{C}$ and mixed with separated $P$. aeruginosa cells. The mixture was allowed to solidify by standing at $4^{\circ} \mathrm{C}$. The hard gel was shredded in a Waring blender and the nonentrapped cells were removed by washing with saline [25].

\section{Biotransformation}

In this method $0.1 \mathrm{gl}^{-1}$ methanol was used as a solubilising agent, added to $100 \mathrm{ml}$ of medium containing $4.47 \mathrm{gl}^{-1}$ myrcene.

\section{Optimum conditions for biotransformation}

For studying the optimum conditions necessary for biotransformation, 500-ml Erlenmeyer flasks were used for obtaining P. aeruginosa PTCC 1074 growth in $250 \mathrm{ml}$ of media; $4.47 \mathrm{~g} \mathrm{l}^{-1}$ myrcene with $0.1 \mathrm{gl}^{-1}$ methanol was added to the medium, $P$. aeruginosa was entered into the media, and a suitable growth phase was determined after which cells could be harvested. This was done by employing different times of growth. An agitation speed of $150 \mathrm{rpm}$ with biotransformation times of 3 days and 1.5 days were employed. The optimum values of $\mathrm{pH}$ and temperature for biotransformation were found to be in the area of $\mathrm{pH} 5.5$ and $27^{\circ} \mathrm{C}$ for both incubation periods (see Figure 1).

\section{Extraction of products}

Extraction of bioconversion products of myrcene after treatment with $P$. aeruginosa was carried out after removing the bacterial cells by centrifugation $(12,800 \mathrm{~g}$, $10 \mathrm{~min}$ ), and the supernatant was extracted with diethyl ether $(3 \times 25 \mathrm{ml})$. The combined extract was washed with distilled water $(3 \times 10 \mathrm{ml})$, dried over anhydrous sodium sulphate and filtered using Whatman No.1 filter paper. The solvent was removed under reduced pressure to give pure reaction products. The products were directly analyzed by FT-IR, UV, GC, and GC-MS.

\section{Analysis of the samples with FT-IR, UV, GC, and GC-MS}

The method described by Speelmans, Bijlsma, and Egglink [26] was employed with some modifications for analysis of the product on a gas chromatograph. The composition in relative percentages was computed by the normalization method from the GC peak areas, and percentage conversion was used as the performance criterion.

GC analysis was performed on a Shimadzu 15A gas chromatograph equipped with a DB5 capillary column (50 m $\times 0.2 \mathrm{~mm}$, film thickness $0.32 \mu \mathrm{m})$. The split/splitless injector and flame ionization detector were heated at $250^{\circ} \mathrm{C}$. N2 was used as the carrier gas $(1 \mathrm{ml} / \mathrm{min})$. The oven temperature was kept at $60^{\circ} \mathrm{C}$ for $3 \mathrm{~min}$ and then heated to $220^{\circ} \mathrm{C}$ at a $5^{\circ} \mathrm{C} / \mathrm{min}$ rate and kept constant at $220^{\circ} \mathrm{C}$ for $5 \mathrm{~min}$. The relative percentage amounts were calculated from the peak area using a Shimadzu C-R4A Chromatopac integrator without correction factor.

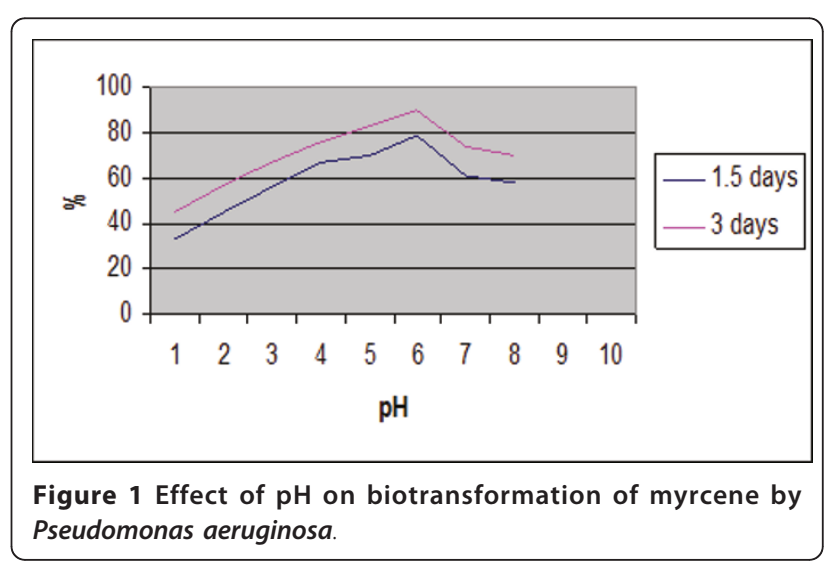


GC-MS analysis was performed using a Hewlett-Packard 5973 equipped with an HP 5MS column $(30 \mathrm{~m} \times$ $0.25 \mathrm{~mm}$, film thickness $0.25 \mu \mathrm{m})$. The oven temperature was kept at $60^{\circ} \mathrm{C}$ for $3 \mathrm{~min}$ and programmed to $220^{\circ} \mathrm{C}$ at a rate of $5^{\circ} \mathrm{C} / \mathrm{min}$ and kept constant at $220^{\circ} \mathrm{C}$ for $5 \mathrm{~min}$. The apparatus operated with helium as the carrier gas at a flow rate of $1 \mathrm{ml} / \mathrm{min}$ in an electronic impact mode of $70 \mathrm{eV}$. Identification of the constituents of the oil was made by comparison of their mass spectra and retention indices with those given in the literature and the authentic samples [27,28]. FT-IR mass spectra (6 main peaks) were recorded in $\mathrm{CHCl}_{3}$ on a Perkin-Elmer 457 instrument. Mass spectra (6 main peaks) of dihydrolinalool (retention time $10.17 \mathrm{~min}$ ), 2,6-dimethyloctane (retention time $12.21 \mathrm{~min}$ ), and $\alpha$-terpineol (retention time $11.18 \mathrm{~min}$ ) are given below:

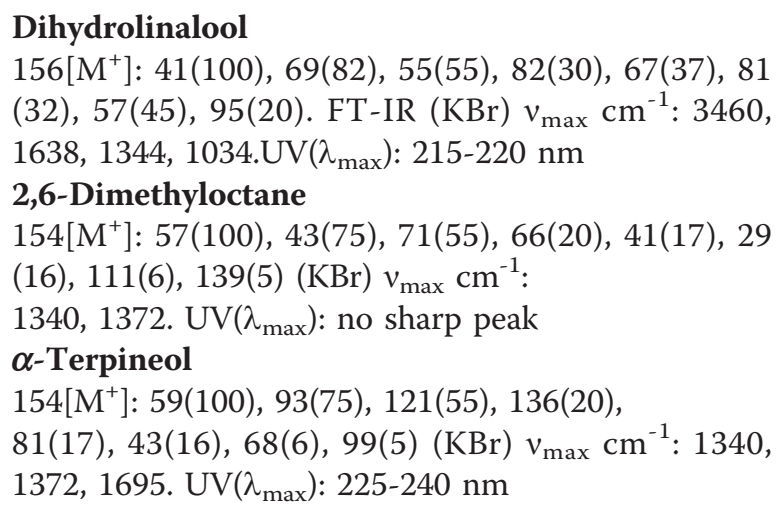

FT-IR (KBr) analysis in dihydrolinalool was $v_{\max } \mathrm{cm}^{-1}$ : $3400(\mathrm{C}-\mathrm{OH}), 1344\left(-\mathrm{CH}_{3}\right.$ or $\left.-\mathrm{CH}_{2}\right)$. For 3 days FT-IR spectra showed for 2,6-dimethyloctane a peak in the region between 1344 and $2945 \mathrm{~cm}^{-1}$ (see Figure 2).

\section{Results}

The study of biotransformation of menthol by sporulated surface cultures of $A$. niger and $P$. sp. produced terpineol and limonene, $p$-cymene, $\gamma$-terpinene, respectively [29]. The two main products of microbial transformation of citral were similar to those obtained in the mentioned works. The main bioconversion products of (-)-menthol by sporulated surface cultures Mucor ramannianus were trans-p-menthan-8-ol, trans-menth2-en-1-ol, sabinane, p-menthane-3, 8-diol, isomenthol, and 1,8-cineole [30]. The main biotransformation products obtained from menthol by surface grown $P$. $s p$. were $\alpha$-pinene $(18.0 \%)$, terpineol $(10.6 \%)$, menthene (5.8\%), sabinene (3.9\%), 1,8-cineole (6.4\%), and limonene (3.2\%) [31]. The experimental work suggested that microbial transformation of monoterpenes with $P$. sp and $A$. niger caused an oxidation reaction and resulted in a more stable product. But bioconversion using $P$. aeruginosa showed it was possible to obtain two products with a high percentage and selectivity.

Products from the biotransformation of myrcene were extracted with diethyl ether $\left(\mathrm{Et}_{2} \mathrm{O}\right)$ three consecutive times and directly analyzed by FT-IR, UV, GC, and GC-MS.

When myrcene was converted with $P$. aeruginosa for 1.5 days, the main products were dihydrolinalool (79.5\%) and 2,6-dimethyloctane (9.3\%). When myrcene was converted for 3 days, the main compounds produced were $\alpha$-terpineol (7.7\%) and 2,6-dimethyloctane (90.0\%) (see Figure 3).

The determination of a suitable culture age during growth of $P$. aeruginosa in medium for maximum product formation was accomplished by harvesting cells in various stages of growth and employing them for myrcene biotransformation. The results indicated the

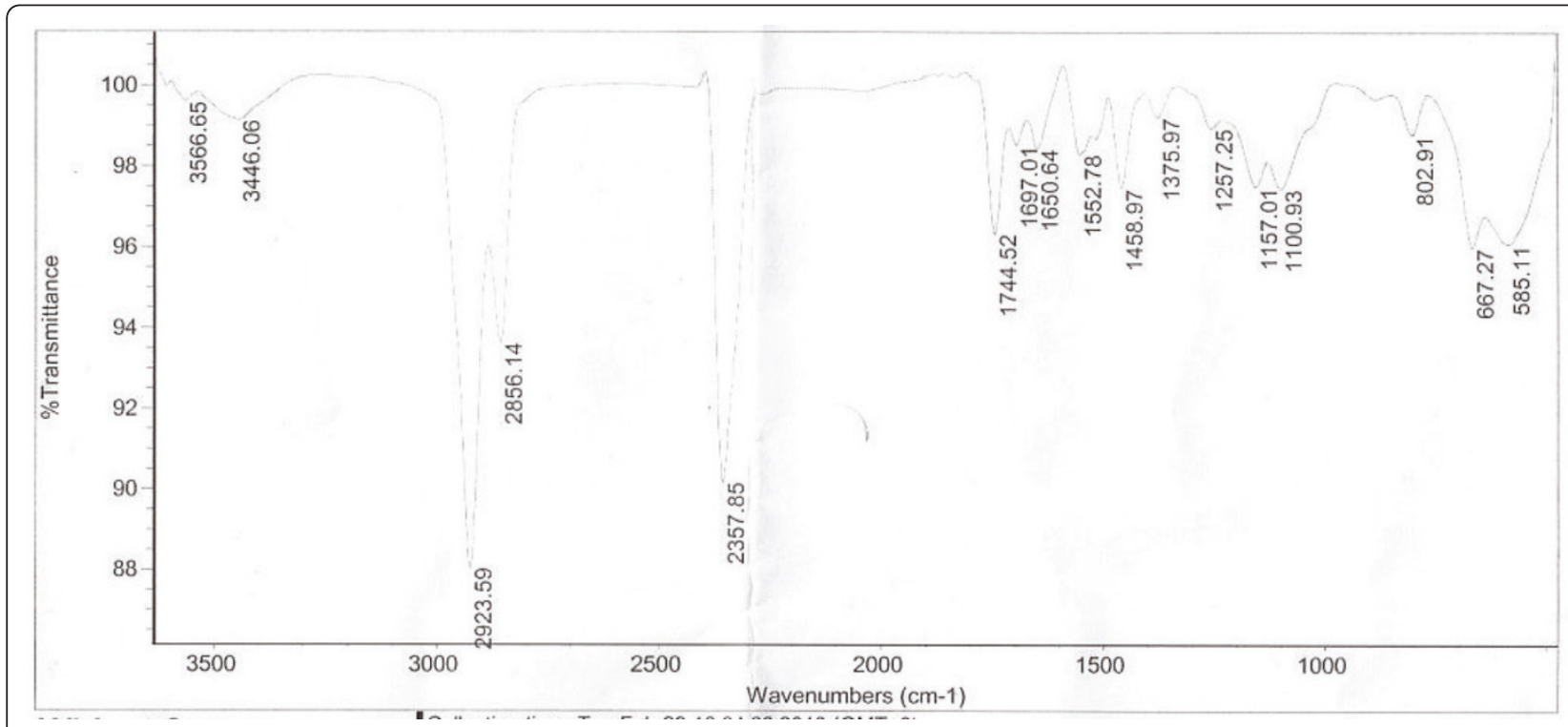

Figure 2 IR spectra for 1.5 days bioconversion by Pseudomonas aeruginosa. 


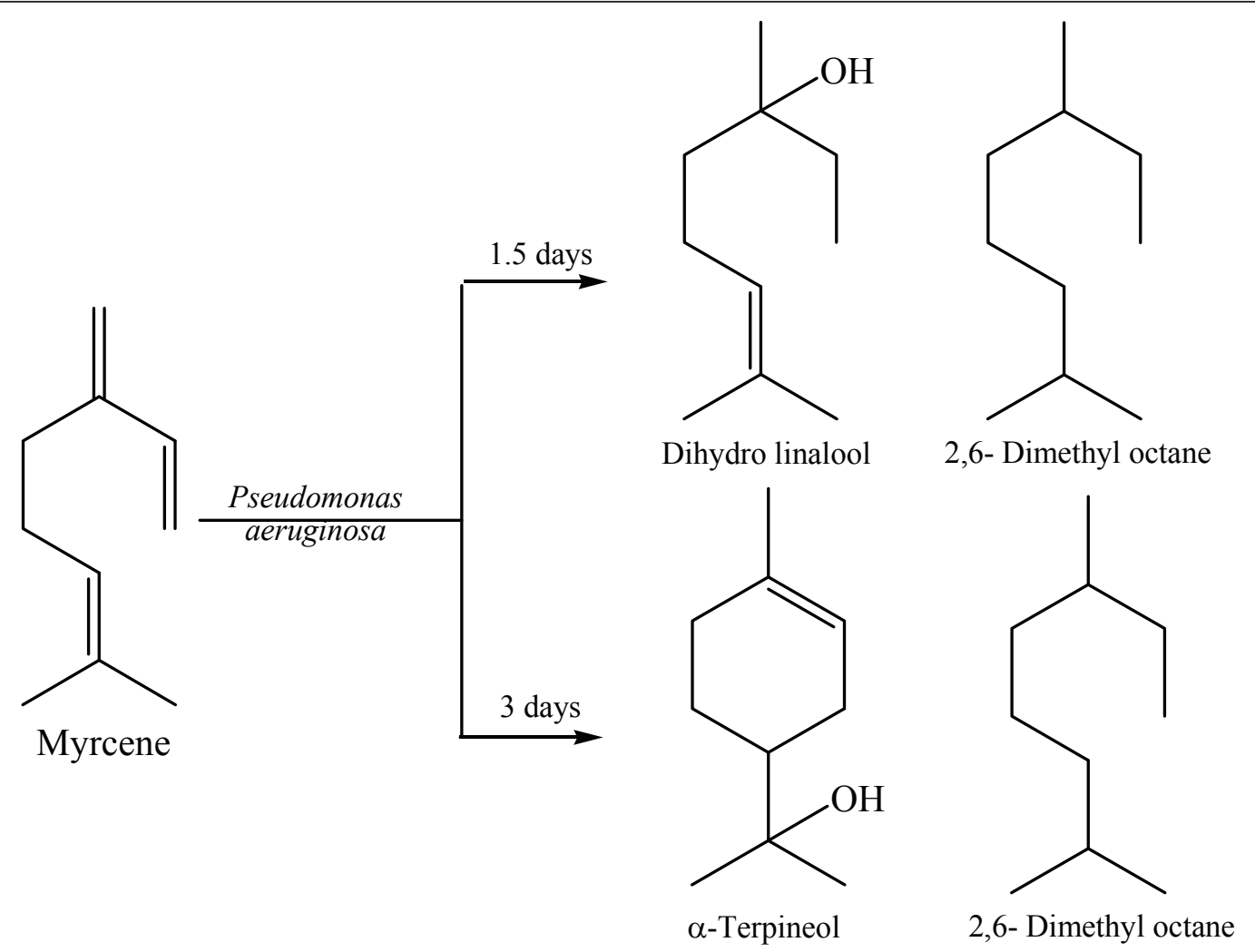

Figure 3 Varying incubation periods in bioconversion of myrcene by Pseudomonas aeruginosa.

optimum cell culture age to be 3 days, with $97.7 \%$ product formation; the product formation for 1.5 days was $88.8 \%$. Here, the cells were at the end of the exponential phase and had attained maximum cell concentration. The optimum substrate concentration to be employed for obtaining maximum product concentrations was done by adding different substrate concentrations to $P$. aeruginosa cell growth.

\section{Discussion}

The purpose of this research was to study the microbial transformation of myrcene by $P$. aeruginosa.

In a previous study of biotransformation of menthol by sporulated surface cultures of $A$. niger and $P$. sp., the main bioconversion product obtained from menthol of A. niger was cis-p-menthan-7-ol, and the main products obtained by sporulated surface cultures of $P$. sp. were limonene, $p$-cymene, and $\gamma$-terpinene [31]. Leuenberger (1984) reported that product yields could be effectively increased by solubilizing/emulsifying immiscible substrates. However, careful selection of the nature and concentration of the solvent is necessary because many miscible solvents are cytotoxic at lower concentrations [31]. The biotransformation of volatile monoterpenoids by fungi was examined. Using 1.5 days and 3 days for biotransformation, we identified two components for each incubation period, representing $88.8 \%$ and $97.7 \%$ respectively (see Figure 3).

Comparing samples of IR spectra showed a peak for 1.5 days in the $3400 \mathrm{~cm}^{-1}$ region, while 3 days did not have signals in the $>3000 \mathrm{~cm}^{-1}$ region for $-\mathrm{OH}$ protons (see Figure 2).

It can be concluded that myrcene was converted primarily to dihydrolinalool, 2,6-dimethyloctane and $\alpha$-terpineol. The reduction of the $\mathrm{C}=\mathrm{C}$ bonds and the formation of an $\mathrm{OH}$ group of $\alpha$-terpineol is achieved by epoxidation of a double bond followed by a reductive ring opening of the epoxide. Myrcene was reduced by $P$. aeruginosa and formed $\alpha$-terpineol (see Figure 4). The GC pattern showed that in 1.5 and 3 days volatile components and monoterpene components mostly exit the column first.

Figures 5 and 6 show GC-MS analysis for bioconversion of 1.5 and 3 days. The best results were obtained at 1.5 and 3 days. In the other incubation periods, the percentage of the components was small and could not be identified.

Of the various values of $\mathrm{pHs}$ tested, $\mathrm{pH} 5.5$ had the best result.

The cited results suggest that microbial transformation of monoterpenes with Penicillium and Aspergillus 


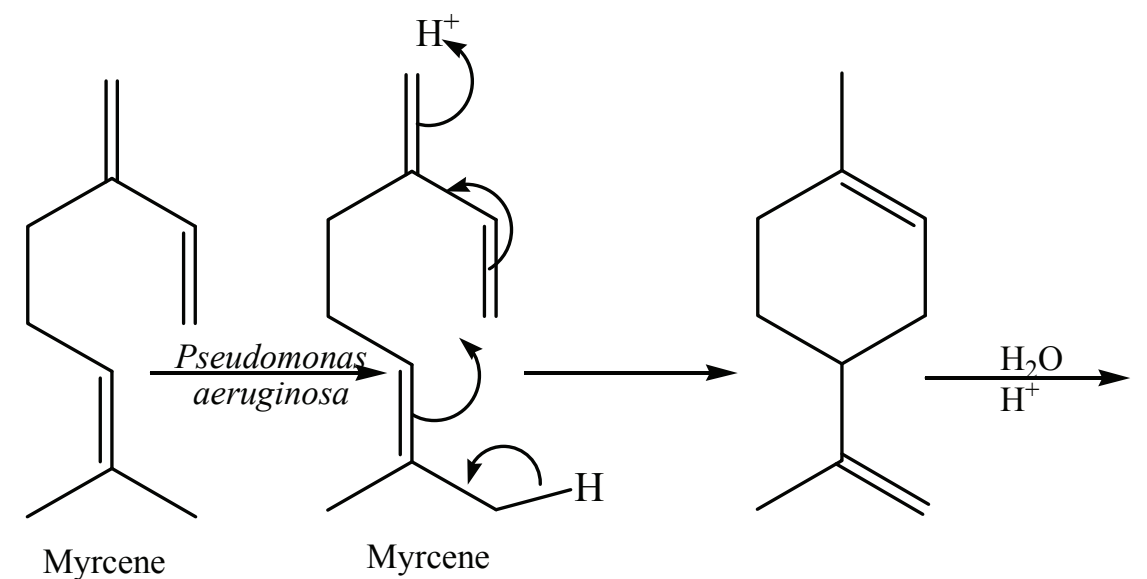

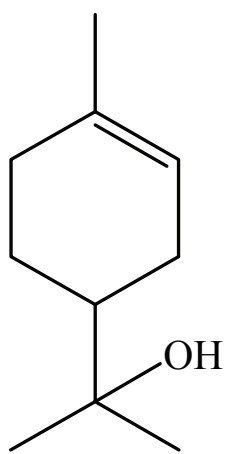

$\alpha$-Terpineol

Figure 4 Bioconversion of myrcene to $\alpha$-terpineol by Pseudomonas aeruginosa.

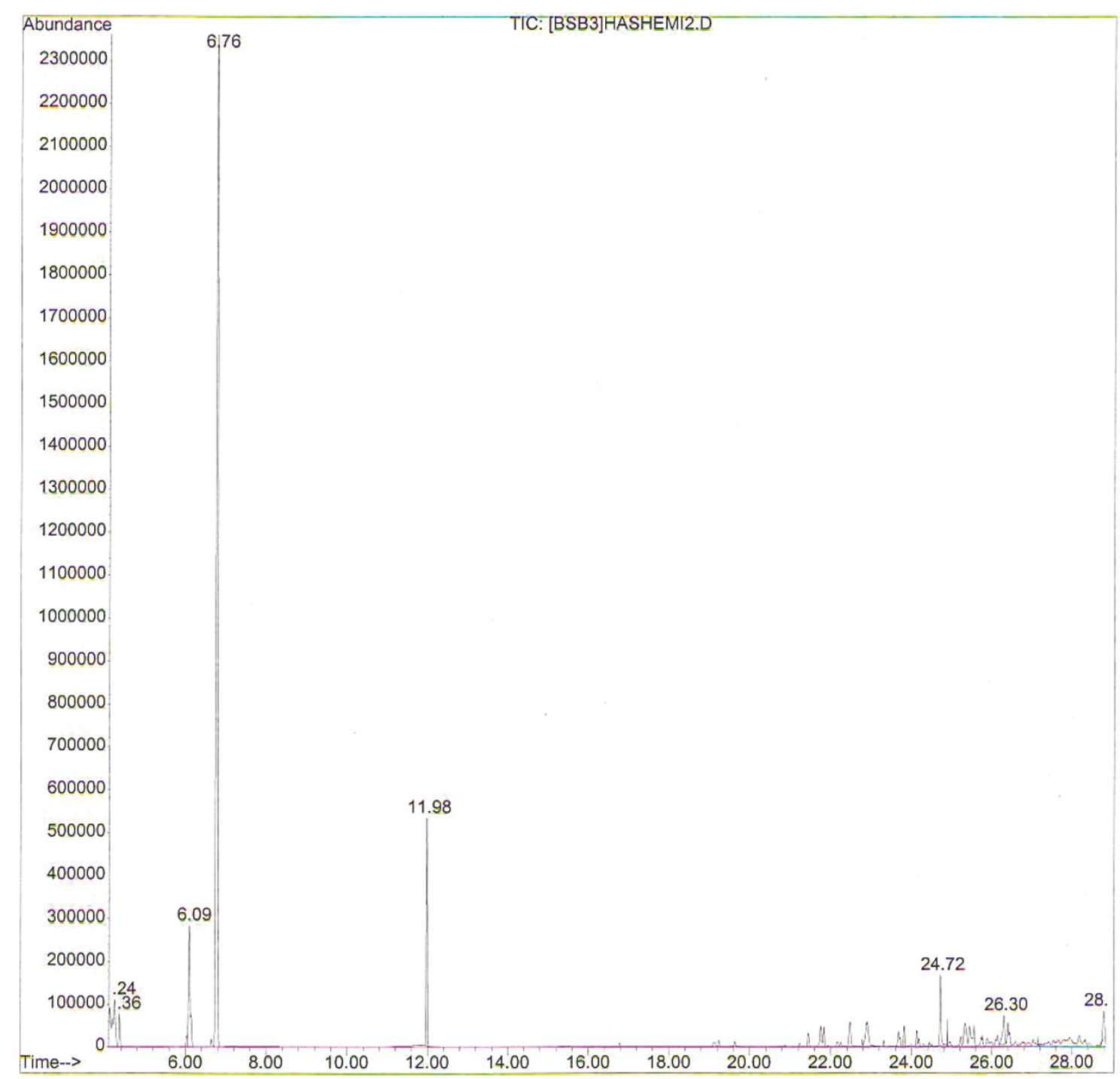

Figure 5 GC-MS analysis for bioconversion of 3 days. 


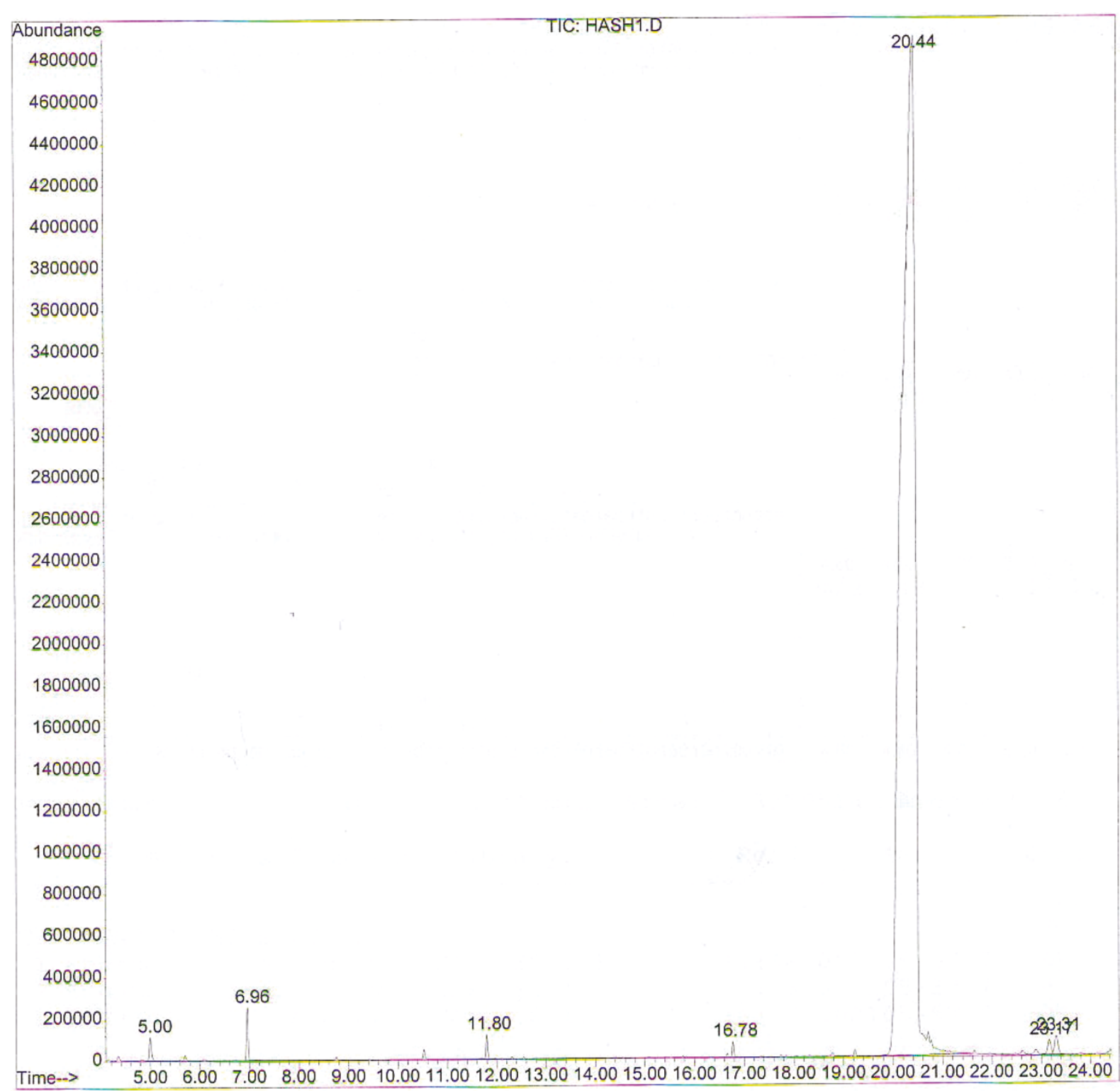

Figure 6 GC-MS analysis for bioconversion of for 1.5 days

involve an oxidation reaction and result in a more stable product. But bioconversion of Penicillium using the sporulated surface cultures and liquid methods demonstrated that it was possible to obtain similar products with high yield and selectivity.

Thymol can be produced by removal of hydrogen and rearrangement of citral. Thymol is present in the essential oils from herbs and spices [32]. It is produced by these plant species as a chemical defense against phytopathogenic microorganisms. Therefore, these compounds have attracted great attention in food industry. They have been used as natural preservatives in foods such as cheese to prevent fungal growth.

\section{Conclusions}

Biosynthesis of myrcene was investigated. The major bioconversion products were confirmed by analysis using FT-IR, UV, GC, and GC-MS. The major components of the microbial transformation of myrcene with $P$. aeruginosa were derived most effectively over a period of 3 days, the major products being 2,6-dimethyldoctane (90.0\%) and $\alpha$-terpineol (7.7\%) and comprising (97.7\%). An incubation period of 1.5 days yielded dihydrolinalool (79.5\%) and 2,6-dimethyloctane (9.3\%), with the main compounds comprising $88.8 \%$.

Dihydrolinalool, 2,6-dimethyloctane, and terpineol are the major products in this method. They have many 
applications in flavoring, extracts, food and drug manufacturing, and as a fragrance ingredient used in decorative cosmetics, fine fragrances, shampoos, toilet soaps, and other toiletries, as well as in noncosmetic products such as household cleaners and detergents. Their use worldwide is in the region of greater than 1,000 metric tons per annum.

\section{Acknowledgements}

The authors wish to thank Ms. Vakili, Department of Marine Sciences and Technologies, Islamic Azad University, North Tehran Branch, Tehran, Iran for assistance with the use of laboratory.

\section{Authors' contributions}

Both authors contributed equally to this manuscript.

\section{Competing interests}

The authors declare that they have no competing interests.

Received: 21 January 2011 Accepted: 24 May 2011

Published: 24 May 2011

\section{References}

1. Larroche C, Gros JB: Batch and continuous heptanone production Caalginate/Eudrasit RL entrapped spores of Penicillium roqueforti application to aroma production. Biotech Bioeng 1989, 34:30-38.

2. Chatterjee T, Bhattacharyya DK: Biotransformation of limonene by Pseudomonas putida. Appl Microb Biotech 2001, 55:541-546.

3. Velankar HR, Heble MR: Biotransformation of (L)-citronellal to (L)citronellol by free and immobilized Rhodotorula minuta. Elect $J$ of Biotech 2003, 6(2):90-103.

4. Madyastha KM, Krishna Murthy NSR: Transformation of acetates of citronellol, geraniol, and dihydrolinalool by Aspergillus niger regiospecific hydroxylation of citronellol by a cell-free system. Appl Microb Biotech 1988, 28:324-329.

5. Madyastha KM, Krishna Murthy NSR: Regiospecific hydroxylation of acyclic monoterpene alcohols by Aspergillus niger. Tetrahedran Lett 1988, 29:579-580.

6. Goto K: Biochemical degradation of geraniol by Aspergillus niger. Obihiro Chikusandaiagaku Gakujutsu Kenkyu Hok 1967, 4:489-496.

7. Jones KH, Trudgill PW, Hopper DJ: Metabolism of $p$-cresol by the fungus Aspergillus fumigatus. Appl Microb Biotech 1993, 59:1125-1130.

8. Kieslich K, Abraham WR, Stumf B, Thede B, Washausen D: Transformation of terpenoids. In Progress in essential oil research. Volume XVI. Edited by: Brunke EJ. Berlin: Walter de Gruyter; 1986:367-394.

9. Trudgill PW: Microbial metabolism of monoterpenes-recent developments. Biodegrad 1990, 1:93-105.

10. Dhavlikar RS, Bhattacharyya PK: Microbiological transformations of terpenes. Part VIII. Fermentation of limonene by a soil pseudomonad. Ind J Biochem \& Biophy 1966, 3:144-157.

11. Kraidman G, Mukherjee BB, Hill ID: Conversion of $d$-limonene into an optically active isomer of $\delta$-terpineol by Cladosporium sp. Bacteriol Pro 1969, 69:63-68.

12. Cadwallader KR, Braddock RJ, Parish ME, Higgins DP: Bioconversion of (+)-limonene by Pseudomonas gladioli. J Food Sci 1989, 54:1241-1245.

13. Tan Q, Day DF: Bioconversion of limonene to a-terpineol by immobilized Penicillium digitatum. Appl Microb Biotech 1998, 49:96-101.

14. Bowen ER: Potential by-products from the microbial transformation of $d$ limonene. >Proceedings of the Florida State Horticultural Society 1975, 88:305-308.

15. Uribe S, Pena A: Toxicity of alleopathic monoterpene suspensions on yeast, dependence on droplet size. J of Chem Ecol 1990, 16:1399-1408.

16. Reddy BS, Wang CX, Samaha H, Lubet R, Steele VE, Kelloff GJ, Rao CV: Chemopreventive of colon carcinogenesis by dietary perillyl alcohol. Cancer Res 1997, 57:420-425.

17. Bardon S, Picard K, Martel P: Monoterpenes inhibit cell growth, cell cycle progression, and cyclin D1 gene expression in human breast cancer cell lives. Nutrition Cancer 1998, 32:1-7.
18. Wood JB: Microbial fermentation of lower terpenoids. Process Biochem $1969,2: 50-52$.

19. Demyttenaere JCR, Carme Herrera M, De Kimpe N: Biotransformation of geraniol, nerol and citral by sporulated surface cultures of Aspergillus niger and Penicillium sp. Phytochemistry 2000, 55:363-373.

20. Demyttenaere JCR, De Pooter HL: Biotransformation of citral and nerol by spores of Penicillium digitatum. Flav and Frag J 1998, 13:1029-1036.

21. Larroche C, Arpah M, Gros JB: Methylketone by Caalginate/Eudrasit RL entrapped spores of Penicillium roqueforti. Enz and Microb Technol 1989, 11:106-112.

22. Massada Y: Analysis of Essential Oil by Gas Chromatography and Mass Spectrometry New York: Wiley; 1976

23. Adams R: Identification of Essential Oil Components by Gas Chromatography/ Mass Spectroscopy Carol Stream, IL: Allured Publ. Corp; 1995.

24. Ramaswami SK, Briscese P, Gargiullo R, Vonngeldern T: In Flavours and Fragrances. A World Perspective. Volume Chapters 1-3. Edited by: Lawrence BM, Mookerjee BD, Willis BJ. Amsterdam: Elsevier; 1988.

25. D'Souza SF: Immobilized cells: Techniques and applications. Ind J of Microb 1989, 29(2):83-117.

26. Speelmans G, Bijlsma A, Egglink G: Limonene bioconversion to high concentrations of a single and a stable product, perillic acid, by a solvent-resistant Pseudomonas putida strain. Appl Microb Biotech 1998, 50(5):538-544.

27. Chen FC, Chenm CF, Wei RD: Acute toxicity of PR toxin, a mycotoxin from Penicillium roqueforti. Toxicology 1982, 20:433-431.

28. Frank RK, Orth R, Ivankovic S, Kuhlmann M, Schmähl D: Investigations on carcinogenic effects of Penicillium caseicolum and $P$. roqueforti in rats. Experentla 1977, 33:515-516.

29. Esmaeili A, Sharafian S, Safaiyan S, Rezazadeh S, Rustaiyan A: Biotransformation of one monoterpene by sporulated surface cultures of Aspergillus niger and Penicillium sp. Nat Prod Res 2009, 23:1058-1061.

30. Esmaeili A, Saad N, Safaiyan S, Rustaiyan A: Biotransformation of (-)menthol by spores of Mucor ramannianus and study of the pathways involved. Herba Polonica 2009, 56(2):51-57.

31. Esmaeili A, Hoseiny Zarea A, Sharafian S, Safaiyan S, Rustaiyan A: Biotransformation of menthol by sporulated surface cultures of Penicillium sp. and study of the pathways involved. Herba Polonica 2009, 55(1):78-83

32. Esmaeili A, Tavassoli A: Microbial Transformation of Citral by Penicillium sp. Acta Biochimica Polonica 2010, 57:265-8.

doi:10.1186/1752-153X-5-26

Cite this article as: Esmaeili and Hashemi: Biotransformation of myrcene by Pseudomonas aeruginosa. Chemistry Central Journal 2011 5:26.

\section{Publish with ChemistryCentral and every scientist can read your work free of charge \\ "Open access provides opportunities to our colleagues in other parts of the globe, by allowing anyone to view the content free of charge." W. Jeffery Hurst, The Hershey Company. \\ - available free of charge to the entire scientific community \\ - peer reviewed and published immediately upon acceptance \\ - cited in PubMed and archived on PubMed Central \\ - yours - you keep the copyright \\ Submit your manuscript here: \\ http://www.chemistrycentral.com/manuscript/<smiles>c1ccccc1</smiles> ChemistryCentral}

